\title{
Leaching Characteristics of Vanadium with Assistant in Sulfuric Acid from Titano- Magnetite
}

\author{
Xiao-bo ZHU* \\ School of Chemistry and Chemical Engineering, \\ Henan Polytechnic University, \\ Jiaozuo, China \\ e-mail: zhuxiaobo0119@126.com
}

\section{Wen-zhong LI}

School of Chemistry and Chemical Engineering, Henan Polytechnic University, Jiaozuo, China e-mail: 393644034@qq.com

\author{
Wang $\mathrm{LI}^{*}$ \\ School of Chemistry and Chemical Engineering, \\ Henan Polytechnic University, \\ Jiaozuo, China \\ e-mail: liwang0805@126.com \\ Shen TANG \\ School of Chemistry and Chemical Engineering, \\ Henan Polytechnic University, \\ Jiaozuo, China \\ e-mail: 329399803@qq.com
}

\begin{abstract}
The recovery of vanadium with calcium fluoride in sulfuric acid medium was put forward from vanadium titanomagnetite in order to enhance the leaching efficiency of vanadium and reduce the environmental pollution. The main factors, leaching mechanism and kinetics analysis of vanadium from vanadium titano-magnetite concentrate were deeply investigated. The results show that the calcium fluoride could obviously increase the recovery of vanadium and enhance leaching efficiency. The recovery of vanadium was increased from $75 \%$ to $92 \%$ with $6 \%$ calcium fluoride. The calcium fluoride could promote the dissolution of $\mathrm{SiO}_{2}$ and the generation of $\mathrm{H}_{2} \mathrm{SiF}_{6}$, which may easily destroy the crystal lattice of magnetite and dissolve the vanadium. The particles of vanadium titano-magnetite were smaller and multihole with calcium fluoride after the acid leaching process. The leaching kinetics could be expressed by the SCM in the process. The apparent rate constant was increased from 0.0017 to 0.0031 with $6 \%$ calcium fluoride at $100{ }^{\circ} \mathrm{C}$, where the apparent activation energy (Ea) of vanadium leaching has been decreased from $36.05 \mathrm{KJ} / \mathrm{mol}$ to $22.17 \mathrm{KJ} / \mathrm{mol}$.
\end{abstract}

Keywords-Vanadium; Kinetics; Calcium fluoride; Acid leaching; Titano-magnetite

\section{INTRODUCTION}

Vanadium is widely applied in ferrous, non-ferrous metallurgy and chemical production due to its superior physical and chemical properties [1]. The vanadium titanomagnetite is important vanadium sources, which has been distributed in many provinces in China and the proven reserves are 9.83 billion tons. The total reserves of $\mathrm{V}_{2} \mathrm{O}_{5}$ in vanadium titano-magnetite reach 25.96 million [2-3]. The recovery of vanadium has been extensively studied from all kinds of vanadium resources [4-6].

The recovery of vanadium from vanadium titanomagnetite mainly includes direct extraction and extraction from vanadium slag after the ironmaking and steelmaking [7-8]. The process of roasting with $\mathrm{NaCl}$ or $\mathrm{Na}_{2} \mathrm{SO}_{4}$ at above $1000^{\circ} \mathrm{C}$ and water leaching was applied for direct extraction, where the air pollution was serious due to the generation of $\mathrm{Cl}_{2}$ and $\mathrm{SO}_{2}$ [9]. The recovery of vanadium from the vanadium slag mainly includes two methods. One is the process of roasting with $\mathrm{Na}_{2} \mathrm{CO}_{3}$, water leaching, purification and precipitation, where the total recovery of vanadium was low [10]. The other process is calcified roasting or direct roasting, acid leaching, solvent extraction and precipitation [11-14]. High consumption of sulfuric acid was needed to obtain high recovery of vanadium in the process [15-16].

The present research work was to study the recovery of vanadium with calcium fluoride in sulfuric acid medium from vanadium titano-magnetite concentrate to enhance leaching efficiency and reduce environmental pollution. Above all, the main influence factors, leaching mechanism and kinetics analysis were in-depth investigated in the process to scientifically explain and confirm the recovery of vanadium.

\section{EXPERIMENT}

\section{A. Materials}

The raw ore of vanadium titano-magnetite was collected from Shanxi province, China. The particle size of the sample was $-0.074 \mathrm{~mm}$ accounting for $100 \%$ with crushing and grinding. The vanadium titano-magnetite concentrate was obtained using low intensity magnetic separation and the sample was analyzed by using inductively coupled plasma-atomic emission spectrometry (ICP-AES). The results is given in Table 1 .

TABLE 1 THE MAIN CHEMICAL COMPOSITION OF VANADIUM TITANO-MANETITE CONCENTRATE (wt. \%)

\begin{tabular}{cccccccc}
\hline Composition & $\mathrm{V}_{2} \mathrm{O}_{5}$ & $\mathrm{TFe}$ & $\mathrm{Al}_{2} \mathrm{O}_{3}$ & $\mathrm{TiO}_{2}$ & $\mathrm{SiO}_{2}$ & $\mathrm{CaO}$ & $\mathrm{Na}_{2} \mathrm{O}$ \\
\hline Content & 1.24 & 59.58 & 1.49 & 2.15 & 4.96 & 1.13 & 0.14 \\
\hline
\end{tabular}


The analytical purity chemical reagents including sulfuric acid and calcium fluoride from Dengke Chemical Reagent Technology Co., Ltd were used. The water used in this study was distilled water.

\section{B. Methods}

The raw ore of vanadium titano-magnetite was crushed and grinded to $-0.074 \mathrm{~mm}$, and then the sample was separated with low intensity magnetic separation to obtain vanadium titano-magnetite concentrate. Then $100 \mathrm{~g}$ sample was mixed calcium fluoride in the sulfuric acid solution with different concentration at liquid to solid ratio of $5 \mathrm{~mL} / \mathrm{g}$. The ore slurry was stirred with using a KX79-1 magnetic heating mixer (China) at the speed of $300 \mathrm{rpm}$ under different conditions of leaching time and temperature. The acid leaching solution was collected by filtration with a SHB-IIIA vacuum suction filter (China). The leaching residue was dissolved in hydrofluoric acid solution and the contents of vanadium and other elements were determined by ICP-AES. The recovery of vanadium was calculated by the following equation.

$$
\alpha=(\mathrm{q}-\mathrm{p}) / \mathrm{q} \times 100 \%
$$

Where: $\alpha$ is the recovery of vanadium $(\%), q$ is the vanadium quantity of sample $(\mathrm{g})$ and $\mathrm{p}$ is the vanadium quantity of leaching residue $(\mathrm{g})$.

\section{C. .Detection measurement}

The contents of element were detected and analyzed by using a Plasma1000 inductively coupled plasma atomic emissios spetrometuy (ICP-AES).

$\mathrm{X}$-ray diffraction (XRD) patterns were obtained by using a Rigaku D/MAX-III X-ray diffraction meter with $\mathrm{Cu} \mathrm{Ka}$ radiation.

A Jeol JSM-5610LV scanning electron microscopy (SEM) was used to observe the surface morphology of vanadium titano-magnetite concentrate and leaching residue.

\section{RESULTS AND DISCUSSION}

\section{A. Effect of Calcium Fluoride}

The effect of calcium fluoride on recovery of vanadium at different sulfuric acid concentration was investigated under the condition of leaching temperature of $100{ }^{\circ} \mathrm{C}$ and reaction time of $60 \mathrm{~min}$. The result is shown in Fig. 1.

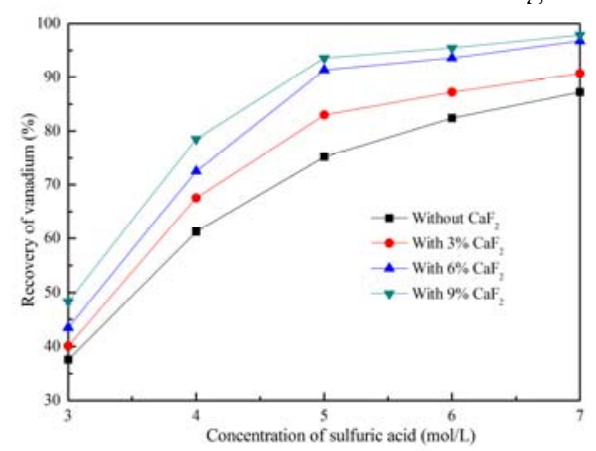

Fig. 1. Effect of calcium fluoride on recovery of vanadium.
It can be seen from Fig. 1 that the recovery of vanadium was increased with increasing calcium fluoride. The recovery of vanadium could reach $75 \%$ with $5 \mathrm{~mol} / \mathrm{L}$ sulfuric acid solution, but $92 \%$ of vanadium was extracted from vanadium titano-magnetite with using $6 \%$ calcium fluoride in the sulfuric acid solution.

\section{B. Effect of Sulfuric Acid Concentration}

The effect of sulfuric acid concentration on recovery of vanadium was investigated under the condition of leaching temperature of $100{ }^{\circ} \mathrm{C}$ and calcium fluoride of $6 \%$. The result is indicated in Fig. 2.
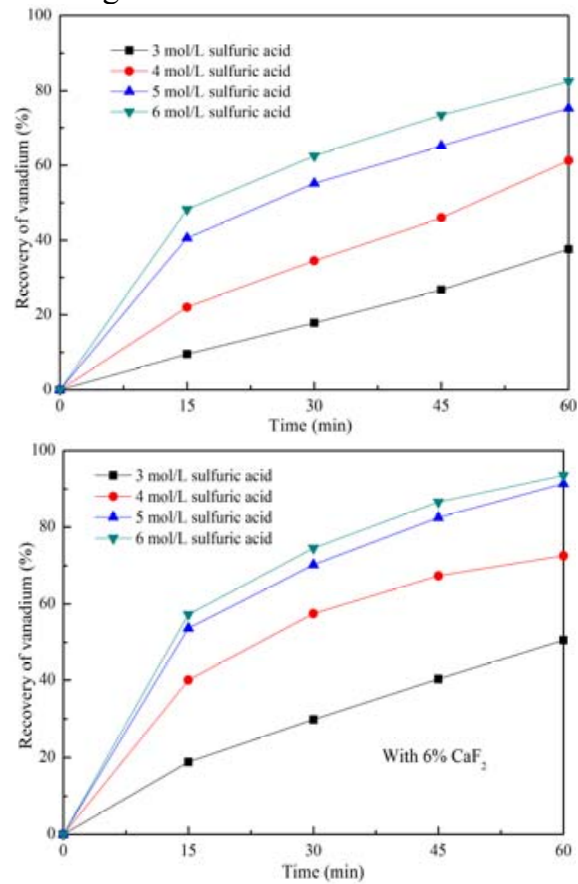

Fig. 2. Effect of sulfuric acid concentration on recovery of vanadium.

It can be observed from Fig. 2 that the recovery of vanadium was obviously increased with increasing sulfuric acid concentration. The increasing tendency was according with increasing reaction time.

\section{Effect of Leaching Temperature}

The effect of leaching temperature on recovery of vanadium was studied under the condition of sulfuric acid of $5 \mathrm{~mol} / \mathrm{L}$ and calcium fluoride of $6 \%$. The result is demonstrated in Fig. 3. 

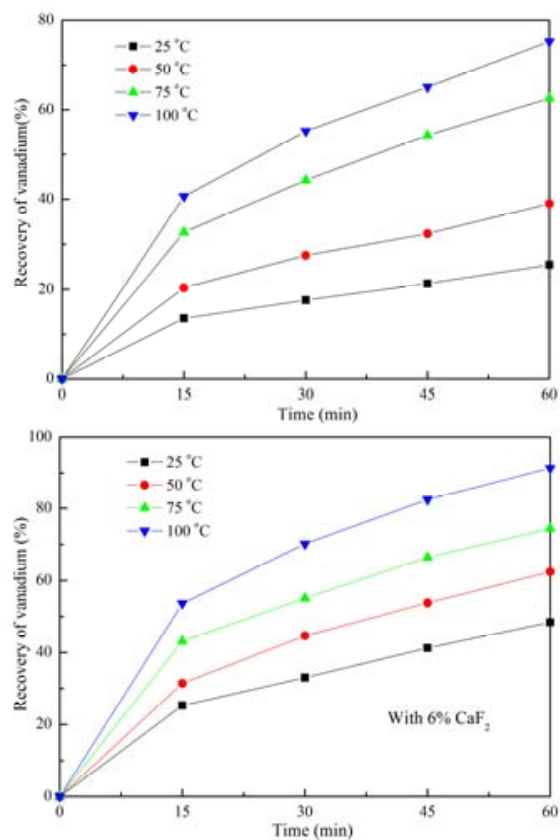

Fig. 3. Effect of leaching temperature on recovery of vanadium.

It is shown in Fig. 3 that the recovery of vanadium was also increased with increasing leaching temperature. However, the increasing tendency of vanadium recovery was more obvious with $6 \%$ calcium fluoride.

\section{Mechanism of Vanadium Leaching}

The effects of calcium fluoride, sulfuric acid concentration and leaching temperature on vanadium recovery were obvious. Therefore, it is important to use a qualitative mechanism with XRD and establish a quantitative measurement of leaching kinetics to confirm the leaching process. The XRD pattern of leaching residue from vanadium titano-magnetite in $5 \mathrm{~mol} / \mathrm{L}$ sulfuric acid is indicated in Fig. 4.

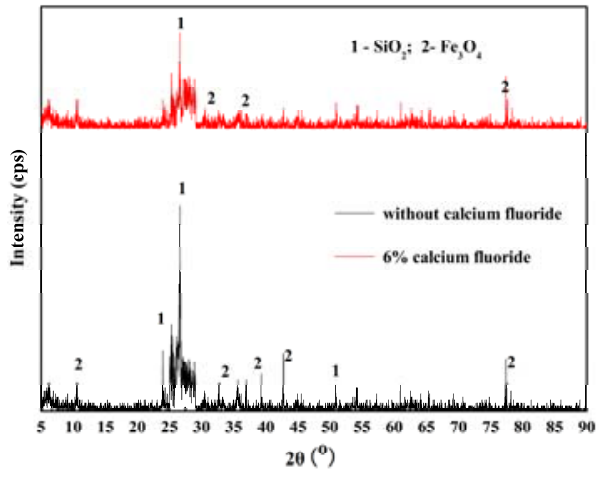

Fig. 4. The XRD pattern of leaching residue with sulfuric acid and calcium fluoride.

It is shown that the phase of ilmenite, omphacite and andesine were disappeared. Some magnetite has been dissolved and the phase of $\mathrm{SiO} 2$ was generated in the acid leaching process without calcium fluoride. However, most phase of $\mathrm{SiO} 2$ and $\mathrm{Fe} 3 \mathrm{O} 4$ were gradually dissolved in the solution with $6 \%$ calcium fluoride.

Therefore, the main chemical and phase reaction could be occurred with calcium fluoride in sulfuric acid solution.

$$
\begin{aligned}
& \mathrm{CaF}_{2}+\mathrm{H}_{2} \mathrm{SO}_{4} \rightarrow 2 \mathrm{HF}+\mathrm{CaSO}_{4} \downarrow \\
& \mathrm{SiO}_{2}+6 \mathrm{HF} \rightarrow \mathrm{H}_{2} \mathrm{SiF}_{6}+2 \mathrm{H}_{2} \mathrm{O}
\end{aligned}
$$

The HF could be generated with calcium fluoride and sulfuric acid at leaching temperature of $100 \mathrm{oC}$. The HF could dissolve $\mathrm{SiO} 2$ and the $\mathrm{H} 2 \mathrm{SiF} 6$ was generated, where the acidity is even stronger than $\mathrm{H} 2 \mathrm{SO} 4$. Therefore, the magnetite and vanadium in the crystal lattice could be easily dissolved in the solution due to the acidity and corrosiveness of HF and H2SiF6[17]. The SEM images of the vanadium titano-magnetite concentrate and acid leaching residue are shown in Fig. 5.

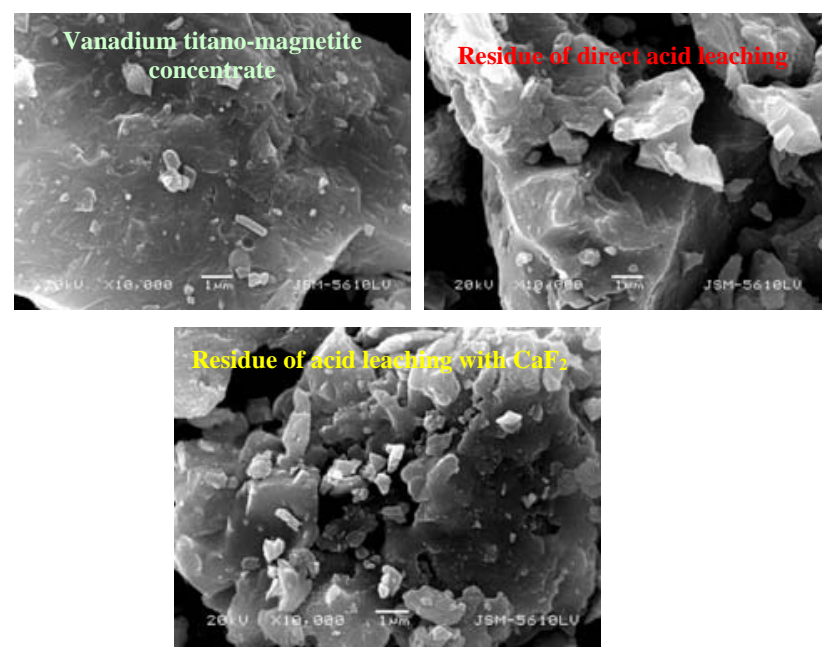

Fig. 5. The SEM images of vanadium titano-magnetite concentrate and leaching residue.

It is indicated from Fig. 5 that the particles of direct leaching residue became small and appeared surface multihole. The particles of leaching residue became multihole and smaller with calcium fluoride, which can be understood that the loose ash layers were generated after the acid leaching process. Therefore, the SCM can be applied in the acid leaching of vanadium from vanadium titanomagnetite concentrate [18-19].

\section{E. Kinetics Analysis of Vanadium Leaching}

According to the SCM, assuming the leaching process is controlled by the internal diffusion, the following expression of leaching kinetics can be used:

$$
\mathrm{k}_{\mathrm{a}} \mathrm{t}=\left[1-2 \alpha / 3-(1-\alpha)^{2 / 3}\right]
$$


Assuming the leaching process is controlled by the chemical reaction, the following expression can be applied for the leaching kinetics:

$$
\mathrm{k}_{\mathrm{b}} \mathrm{t}=\left[1-(1-\alpha)^{1 / 3}\right]
$$

Two controlling steps of the SCM were investigated under different sulfuric acid concentration without calcium fluoride. The result is shown in Fig 6

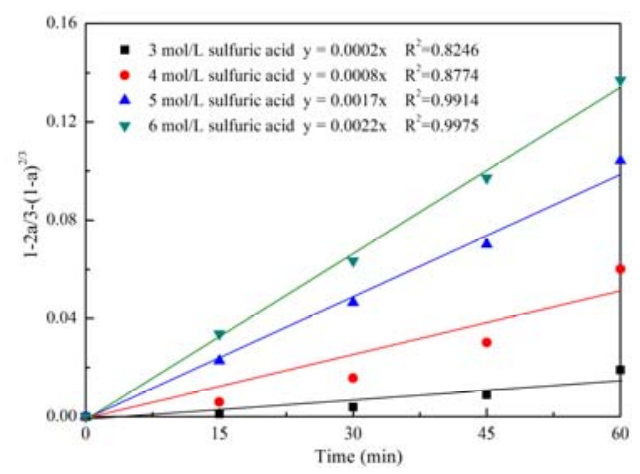

Fig. 6(a). Plots of 1-2 $\alpha / 3-(1-\alpha) 2 / 3$ versus time at different sulfuric acid concentration without calcium fluoride.

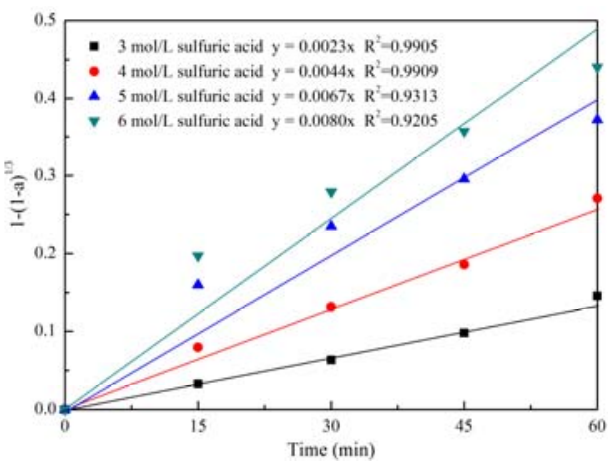

Fig. 6(b). Plots of 1-(1- $\alpha) 1 / 3$ versus time at different sulfuric acid concentration without calcium fluoride.

It is indicated that the control of internal diffusion fitted the leaching data well at $5 \mathrm{~mol} / \mathrm{L}$ and $6 \mathrm{~mol} / \mathrm{L}$ sulfuric acid. The control of chemical reaction control fitted the leaching data well at $3 \mathrm{~mol} / \mathrm{L}$ and $4 \mathrm{~mol} / \mathrm{L}$ sulfuric acid.

Two controlling steps of the SCM were investigated under different sulfuric acid concentration with $6 \%$ calcium fluoride. The result is indicated in Fig 7.

It is shown that the control of internal diffusion fitted the leaching data well at $4 \mathrm{~mol} / \mathrm{L}, 5 \mathrm{~mol} / \mathrm{L}$ and $6 \mathrm{~mol} / \mathrm{L}$ sulfuric acid. Therefore, the addition of calcium fluoride promoted chemical reaction and decreased the consumption of sulfuric acid.

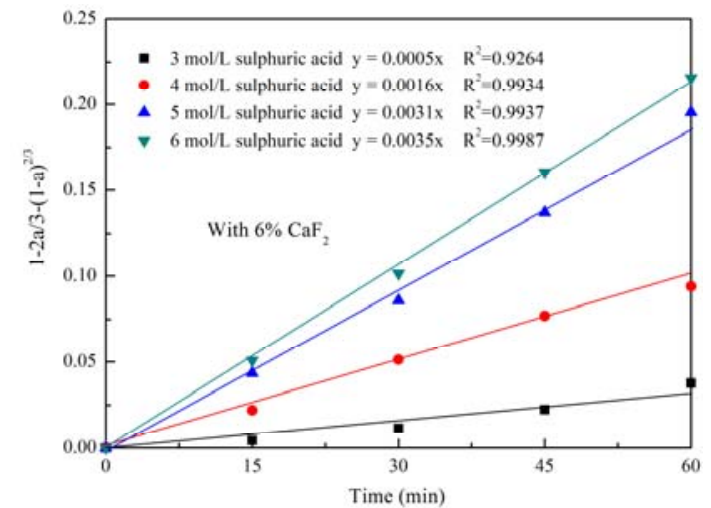

Fig. 7(a). Plots of 1-2 $\alpha / 3-(1-\alpha) 2 / 3$ versus time at different sulfuric acid concentration with calcium fluoride.

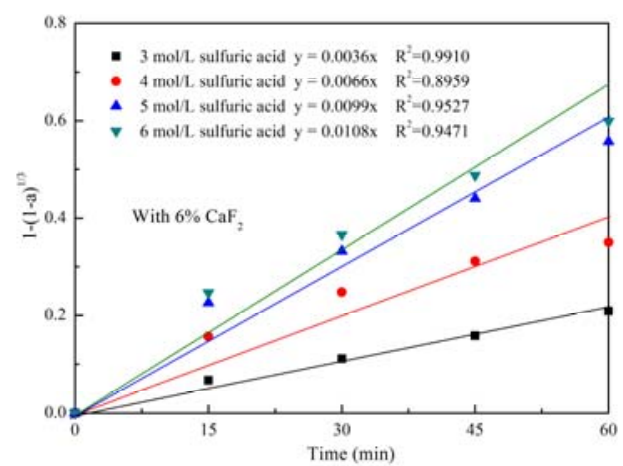

Fig. 7(b). Plots of 1-(1- $\alpha) 1 / 3$ versus time at different sulfuric acid concentration with calcium fluoride.

The internal diffusion controlling steps of the SCM were investigated under different temperature. The result is shown in Fig 8.

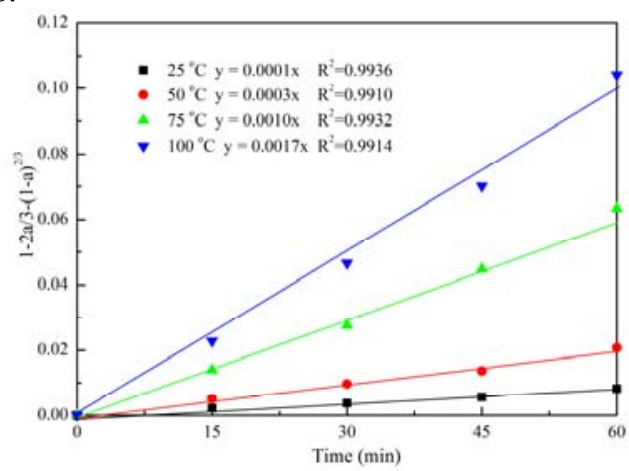

Fig. 8(a). Plots of $1-2 \alpha / 3-(1-\alpha) 2 / 3$ versus time at different temperature without calcium fluoride. 


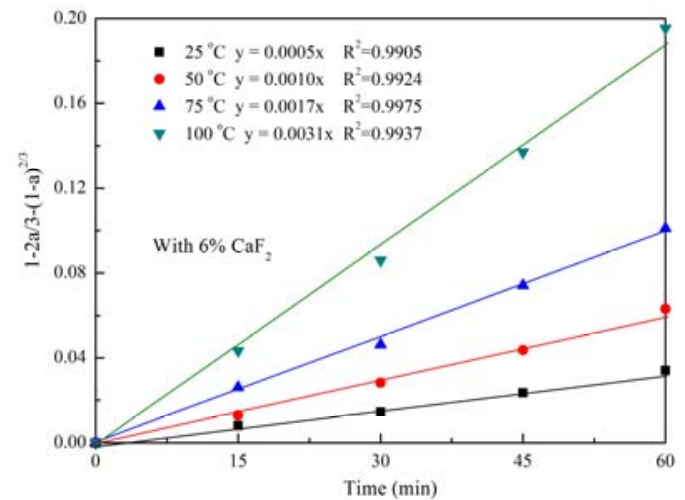

Fig. 8(b). Plots of 1-2 $\alpha / 3-(1-\alpha) 2 / 3$ versus time at different temperature with calcium fluoride.

It can be seen that the control of internal diffusion also fitted the leaching data well and the correlation coefficient (R2) was above 0.99 at different temperature. The speed constants could increase from 0.0017 to 0.0031 at $100 \mathrm{oC}$ with $6 \%$ calcium fluoride. According to the speed constants at different temperatures, the plot of $\ln (\mathrm{ka})$ versus temperature was investigated in Fig 9.

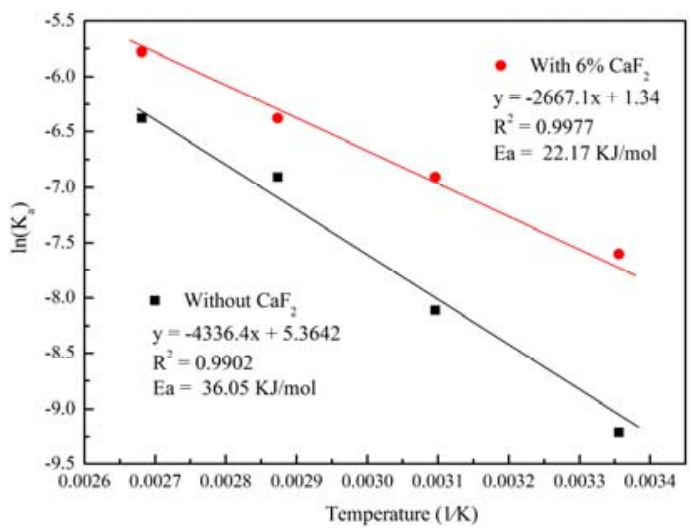

Fig. 9. Plot of $\ln (\mathrm{Ka})$ versus temperature of vanadium leaching.

It can be observed that the correlation coefficient (R2) was above 0.99 at different temperature. The apparent activation energy $(\mathrm{Ea})$ of vanadium leaching was decreased from $36.05 \mathrm{KJ} / \mathrm{mol}$ to $22.17 \mathrm{KJ} / \mathrm{mol}$ with $6 \%$ calcium fluoride by the calculation. The decrease of apparent activation energy can effectively enhance the leaching efficiency based on the theory of kinetics.

\section{CONCLUSIONS}

(1) The recovery of vanadium could reach $92 \%$ under the conditions of calcium fluoride of $6 \%$, sulfuric acid concentration of $5 \mathrm{~mol} / \mathrm{L}$, leaching temperature of $100{ }^{\circ} \mathrm{C}$, liquid to solid ratio of $5 \mathrm{~mL} / \mathrm{g}$ and reaction time of $60 \mathrm{~min}$. The hydrofluoric acid could be generated with calcium fluoride and sulfuric acid at $100{ }^{\circ} \mathrm{C}$. The hydrofluoric acid could promote the dissolution of $\mathrm{SiO}_{2}$ and generation of
$\mathrm{H}_{2} \mathrm{SiF}_{6}$, which may obviously destroy the crystal lattice of magnetite.

(2) The particles of vanadium titano-magnetite concentrate became smaller and multihole with calcium fluoride after the acid leaching process. The leaching kinetics could be expressed by the SCM. The addition of calcium fluoride could promote chemical reaction controlling to internal diffusion controlling. The speed constant was 0.0031 at $100{ }^{\circ} \mathrm{C}$ and $\mathrm{Ea}$ of vanadium leaching was $22.17 \mathrm{KJ} / \mathrm{mol}$ with $6 \%$ calcium fluoride in $5 \mathrm{~mol} / \mathrm{L}$ sulfuric acid. The decrease of Ea has enhanced the leaching efficiency.

\section{ACKNOWLEDGMENT}

The authors are thankful for financial support from the Key Project of Scientific Research in Colleges and Universities from Henan Province (15A440014, 16A530006), the Fundamental Research Funds for the Universities of Henan Province (NSFRF140112) and the Doctoral Foundation from Henan Polytechnic University (B2014-012, B2014-009).

\section{REFERENCES}

[1] X. H. Liu, G. S. Gui, Y. F. Yang, Z. T. Sui, L. Li and J. X. Fu, "Kinetics of the leaching of TiO2 from Ti-bearing blast furnace slag", International Journal of Mining Science and Technology, vol. 18, 2008, pp. 275-278.

[2] J. L. Zhang, X. B. Xing, M. M. Cao, K. X. Jiao, C. L. Wang and R. S. Ren, "Reduction kinetics of vanadium titano-magnetite carbon composite pellets adding catalysts under high temperature", International Journal of Iron and Steel Research, vol. 20, 2013, pp. 17.

[3] H. D. Qiu, H. Zhang, B. Zhao, J. F. Zhu and D. R. Liu, "Dynamics study on vanadium extraction technology from chloride leaching steel slag", Rare Metal Materials and Engineering, vol. 42, 2013, pp. 696699

[4] Q. G. Xiao, Y. Chen, Y. Y. Gao, H. B. Xu and Y. Zhang, "Leaching of silica from vanadium-bearing steel slag in sodium hydroxide solution", Hydrometallurgy, vol. 102, 2010, pp. 216-221.

[5] R. R. Moskalyk and A. M. Alfantazi, "Processing of vanadium: a review”, Mineral Engineering, vol. 16, 2003, pp. 793-805.

[6] M. D. Okudan, A. Akcil, A. Tuncuk and H. Deveci, "Effect of parameters on vanadium recovery from by-pr oducts of the Bayer process", Hydrometallurgy, vol 152, 2015, pp.76-83.

[7] L. J. Li, L. Zhang, S. L. Zheng and T. P. Lou, "Acid leaching of calcined vanadium titanomagnetite with calcium compounds for extraction of vanadium", The Chinese Journal of Process Engineering, vol. 11, 2011, pp. 573-578.

[8] Y. F. Guo, Y. L. Sui, T. Jiang and Y. N. Lu, "Research on leaching vanadium from vanadium and titanium-bearing tailings produced in reduction, grinding and separation of vanadium-bearing titaniferous magnetite", Iron Steel Vanadium Titanium, vol. 3, 2014, pp. 9-15.

[9] E. Hukkanen and H. Walden, "The production of vanadium and steel from titanomagnetites", International Journal of Mineral Processing, vol. 15, 1985, pp.89-102.

[10] X. S. Li, B. Xie, G. E. Wang and X. J. Li, "Oxidation process of lowgrade vanadium slag in presence of $\mathrm{Na}_{2} \mathrm{CO}_{3}$ ", Transcations of Nonferrous Metals Society of China, vol. 21, 2011, pp. 1860-1867.

[11] W. C. Song, H. Li, F. X. Zhu, K. Li and Q. Zheng, "Extraction of vanadium from molten vanadium bearing slag by oxidation with pure oxygen in the presence of CaO", Transcations of Nonferrous Metals Society of China, vol. 24, 2014, pp. 2687-2694.

[12] Z. Yang, H. Y. Li and X. C, "Leaching kinetics of calcification roasted vanadium slag with high $\mathrm{CaO}$ content by sulfuric acid", 
International Journal of Mineral Processing, vol. 133, 2014, pp. 105111.

[13] Z. G. Deng, C. Wei, X. B. Li, H. S. Xu, M. T. Li, C. X. Li and G. Fan, "Leaching vanadium from extracted vanadium residue of vanadium titanomagnetite", The Chinese Journal of Nonferrous Metals, vol.22, 2012, pp. 1170-1177.

[14] K. T. Huang and X. D. Wang, "Extraction of vanadium from vanadium mica by liming roasting", Journal of Wuhan Iron Steel University, vol. 15, 1992, pp. 335-339.

[15] Y. M. Zhang, X. B. Zhu, J. Huang and T. Liu, "Effect of colloidal potassium alum formation on vanadium recovery from acid leach solutions of stone coal", Hydrometallurgy, vol. 138, 2013, pp. 54-58.
[16] W. Li, Y. M. Zhang, J. Huang, X. B. Zhu and Y. Wang, "Separation and recovery of sulfuric acid from acidic vanadium leaching solution by diffusion dialysis", Separation and Purification Technology, vol. 96, 2012, pp. 44-49.

[17] F. Wang, Y. M. Zhang, J. Huang, T. Liu, J. Zhao and G. B. Zhang, "Acid-leaching of vanadium from stoal coal with calcium fluoride addition", Chinese Journal of Rare Metals, vol.37, 2013, pp. 628-634.

[18] D. C. Mo, "Metallurgical Kinetic", South China Industrial University Press, Changsh, 1988, pp. 283-290.

[19] X. B. Zhu, Y. M. Zhang, J. Huang, T. Liu and Y. Wang, "A kinetics study of multi-stage counter-current circulation acid leaching of vanadium from stone coal", International Journal of Mineral Processing, vol. 114-117, 2012, pp. 1-7. 